\title{
Initial Knowledge at Radiation Protection Courses from 2005-2013 (3): Tendencies and Conclusions
}

\author{
Initialer Kenntnisstand bei Strahlenschutzkursen von 2005-2013 (3): \\ Tendenzen und Folgerungen
}

Authors

Affiliations
U. F. Haverkamp' ${ }^{1}$, B. A. Pruemer², A. Fahrmer ${ }^{3}$

Department of Radiotherapy, University of Münster

Institute of Radiology, Herz-Jesu Hospital, Münster

Jurist, ASPIXpro, Bonn
Key words

- EU directive $97 / 43$

- refresher course

- follow-up test

eingereicht 11.9.2012

akzeptiert $\quad 1.5 .2013$

Bibliography

Dol http://dx.doi.org/

10.1055/s-0033-1335677

Published online: 26.7.2013

Fortschr Röntgenstr 2013; 185 :

1070-1073 @ Georg Thieme

Verlag KG Stuttgart · New York . ISSN 1438-9029

\section{Correspondence \\ Herr Dr. Uwe Friedrich Haverkamp}

Klinik für Strahlenheilkunde, Universität Münster

Albert-Schweitzer-Campus 1

48149 Münster

Tel.: ++ 49/2 51/8347359

Fax: ++ 49/2 51/8347355

Uwe.Haverkamp@

ukmuenster.de

\section{Abstract}

Purpose: The necessity of refresher courses is controversial and is frequently questioned. The present study examines whether the courses have a lasting effect and whether improvements are indicated.

Materials and Methods: With the help of a questionnaire (9 questions) to be answered before the course, a self-assessment was performed and questions about the knowledge and structure of radiation protection were asked. 1361 participants were surveyed (55\% physicians, $31 \%$ doctor's assistants, $13 \%$ technicians, $1 \%$ medical physicists) in the period of 2005 2013 (3) and 39 courses were evaluated. The assessment entailed the comparison of 3 subgroups: 2005 - 2007, 2008 - 2010, 2011 - 2013.

Results: The self-assessment is about 3.0 ( 1 - very good, 5 - very poor) with fluctuations regarding time course and occupation. For all questions, there was an increase in correct answers from the period 2005 - 2007 to the period $2008-2010(+15 \%)$, while the rate fell again for the period $2011-2013$ (3) (-8\%). The questions were answered significantly better for organization-related topics than knowledge-based topics. Overall $53 \%$ of the answers were correct. Conclusion: This study shows an increase in knowledge since starting refresher courses. However, recently the effect has decreased again. In order to maintain the knowledge, the yearly instruction must be held on time, which according to participants' statements actually occurs in only $60 \%$ of cases.

Key Points:

- Insufficient knowledge

- Refresher courses not be retained sufficiently

- Adaption of training time and interval Citation Format:

- Haverkamp UF, Pruemer BA, Fahrmer A. Initial Knowledge at Radiation Protection
Courses from 2005-2013 (3): Tendencies and Results. Fortschr Röntgenstr 2013; 185: 1070-1073

\section{Zusammenfassung \\ $\nabla$}

Ziel: Die Notwendigkeit von Aktualisierungskursen ist umstritten und wird häufig angezweifelt. Die vorliegende Studie untersucht, ob diese Kurse eine nachhaltige Wirkung haben und ob Verbesserungen angezeigt sind.

Material und Methoden: Mithilfe eines Fragebogens (9 Fragen), der vor dem jeweiligen Kurs zu beantworten war, wurde eine Selbsteinschätzung erhoben und es wurden Fragen zum Wissen über und zur Struktur des Strahlenschutzes gestellt. 1361 Teilnehmer wurden von 20052013 (3) befragt (55\% Ärzte, 31\% Pflegende und Arzthelferinnen, $13 \%$ MTRs, $1 \%$ Physiker), dabei wurden 39 Kurse ausgewertet. Die Auswertung erfolgte über den Vergleich von 3 Gruppen: 2005 - 2007, 2008 - 2010, 2011 - 2013.

Ergebnisse: Die Selbsteinschätzung liegt um 3,0 (1 - sehr gut, 5 - mangelhaft), mit Schwankungen über den Zeitverlauf und die Berufsgruppen. Für alle Fragen gab es einen Anstieg richtiger Antworten von $2005-2007$ auf $2008-2010$ (+15\%), danach fiel für 2011 - 2013 (3) die Quote wieder ab $(-8 \%)$. Dabei werden die Fragen nach der Organisation deutlich besser beantwortet als Kenntnisfragen. Im Mittel über alle Jahre wurden $53 \%$ aller Fragen richtig beantwortet.

Schlussfolgerung: Die Untersuchung zeigt einen zunehmenden Kenntnisgewinn mit Einführung der Aktualisierungskurse, der über die letzten 3 Jahre aber wieder abnimmt. Um den Kenntnisstand zu bewahren, wäre es eine Möglichkeit, die nach Angaben der Teilnehmer nur zu 60\% fristgerecht stattfindenden Unterweisungen $\mathrm{zu}$ stärken. 


\section{Introduction}

\section{$\nabla$}

As part of the implementation of EU Directive 97/43 [1], refresher courses were mandated in Germany for all qualified persons and persons with knowledge according to the X-Ray Protection Ordinance and the Radiation Protection Ordinance [2-4]. These courses must be attended "at least every 5 years" to maintain qualification. This also means that the courses must be successfully completed with an exam at the end of the $5^{\text {th }}$ year at the latest. The goal of these courses is to refresh and update radiation protection knowledge and in particular to impart information about new legal regulations and new scientific findings. The objective of the present study was to determine whether the courses increase knowledge in a lasting way and whether improvement potential can be derived from the courses that have been conducted to date.

\section{Background \\ $\nabla$}

The purpose of Directive 97/43/EURATOM [1] is to strengthen radiation protection and increase radiation protection awareness and knowledge in Europe. Due to the legal situation in Europe, EU directives generally do not become immediately effective but instead require transformation into national law in the member states [1]. In this process the objectives are binding but the implementation plan can be determined by each state and the terms can even be made stricter. The directive includes a statement of requirements that must be implemented by 2001. In Germany, the directive was implemented with the amendment of the X-Ray Ordinance in a revision [2] in 2003 and with the amendment of the Radiation Protection Ordinance in a revised version [4] in 2001. The mandated refresher courses are described in greater detail in the guideline on qualification and knowledge in radiation protection [5]. New radiation protection findings and changes in the regulations are expressly named as main reasons for the amendment of the X-Ray Ordinance.

\section{Materials and Methods

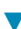

Following a preliminary study [6], a questionnaire was developed and included a self-assessment and technical questions regarding various radiation protection topics. Course participants between the years 2005 and 2013 (3), totaling 1361 participants, were surveyed on the day of the course just prior to the start of the course. The courses were offered as combined courses (X-Ray Ordinance and Radiation Protection Ordinance) as well as individual courses in accordance with the X-Ray Ordinance. This study included a total of 3 cycles of courses and an assessment was performed for the years 2005-2007, 2008-2010, and 2011-2013 (3). Time periods were selected to prevent the statistical fluctuations of individual courses from affecting the evaluation. The schema 3-3-3 was selected since there was an increase in incorrect answers in 2011. The participants came from every occupational group dealing with ionizing radiation (physicians 55\%, technicians $13 \%$, physicists $1 \%$, medical assistants $19 \%$, nursing staff $12 \%$ ). Cross-occupational courses were conducted based on the didactic idea that those deter- mining the indication for examination and those performing the examination should attend the same course. The areas of specialization of the participating physicians were as follows: radiology and radiation therapy $8 \%$, internal medicine $24 \%$, surgery $17 \%$, orthopedics $15 \%$, anesthesiology $13 \%$, other $23 \%$. The relatively high percentage of participants from the field of internal medicine cannot be definitively explained but based on the statistics regarding licenses to practice as a statutory health insurance-authorized physician [7] and under consideration of only radiological areas of specialization, the percentage of physicians practicing internal medicine exclusively is approximately $20 \%$, which corresponds to the percentage in this study.

The questionnaires were distributed and completed immediately prior to the start of the courses and were quickly reviewed by the lecturers during the course day. Preliminary information about the participants, previous courses, prior instructions, or additional information sources was not known. Therefore, the participants' knowledge at the time of the course and their knowledge retention over time could be evaluated. The goal was to obtain basic information about the level of radiation protection knowledge with minimal questions.

In total, 39 courses held in three states (North Rhine-Westphalia, Lower Saxony, and Hessen) were evaluated. The average number of participants was $35(18-106)$ and the response rate was $95 \%$. The goal was to determine the initial level of knowledge of the participants in order to be able to evaluate the effectiveness of preceding courses and the participants' knowledge retention and additionally to adapt the content of current courses based on the responses to the questions.

The questions related to the management of radiation protection in each participant's own organization (instruction, medical examination, knowledge of the result of personal dosimetry), self-organization (knowledge of the radiation protection supervisor, reading of the X-Ray Ordinance, knowledge of the presence of a copy of the X-Ray Ordinance "whether and where") and own radiation protection knowledge (limit value in category A, pregnant women in the controlled area). The questions are listed in $\bullet$ Table 1. The topics were adapted to the legal regulations (guideline on qualification and knowledge in radiation protection [5]). The self-assessment responses were given on a scale of $1-5$ (1: very good to 5 : very poor).

\section{Results}

\section{$\nabla$}

The average self-assessment value was about 3.0 with minor variations over the years 2005-2013 (3) from 3.2 to 2.9 to 3.1. At the start, the medical assistants rated themselves with 2.9, the technicians with 3.0, the physicians with 3.2, and the nursing staff with 3.4.

If all responses are viewed together, $43 \%$ of the answers were correct in the first observation period, $59 \%$ in the second period, and $52 \%$ in the period from $2011-2013$ (3). - Table 1 shows the evaluation according to period, which makes it clear that a categorization according to the years $2005-2007,2008-2010,2011-2013$ (3) can result in a useful interpretation. 
Table 1 Questionnaire results evaluated according to three-year periods. The arrows indicate the tendency from period to period, and the p-values indicate the level of significance.

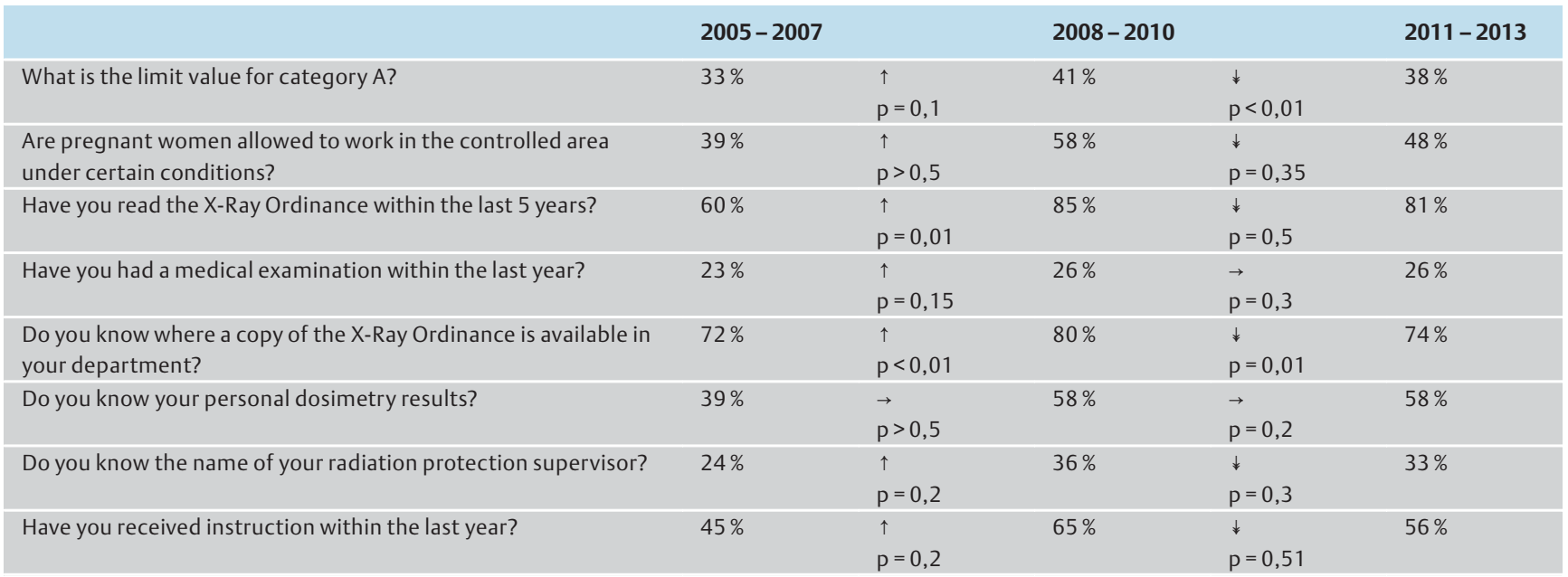

Answers to the questionnaire according to the yearly dose limit (category A) for occupational exposure, authorization for a pregnant worker to be in the controlled area, reading of the X-Ray Ordinance within 5 years, occupational medical examination within the last year, information as to where a copy of legal regulations (X-Ray Ordinance) can be found, knowledge of the personal dose values, knowledge of the name of the radiation protection supervisor and yearly radiation protection instructions.

The questions regarding self-organization, e.g. knowledge about the storage location of the X-Ray Ordinance and the reading of the ordinance, clearly showed an effect that can also be observed for other parameters: In the first period $72 \%$ of the participants knew where to find a copy, while the number increased to $86 \%$ in the following period but then decreased again to $74 \%$ in the period from $2011-$ 2013 (3) ( Table 1). In the first period $60 \%$ of the participants had read the X-Ray Ordinance in the last 5 years, while this number increased to $85 \%$ and $81 \%$, respectively, in the following two periods (during training, prior to the last update, or current). Between $10 \%$ and $17 \%$ of the participants had read the ordinance at least one year prior to the refresher course. $24 \%$ of participants knew the name of the radiation protection supervisor in the first period. This value increased to $36 \%$ in the second period and then fell to $33 \%$ in the third period.

The quality of radiation protection management can be seen in the conducting of instruction and medical examinations according to the specifications for persons occupationally exposed to radiation in category $A$. In the years $2005-2007,45 \%$ of those surveyed stated that an instruction had been conducted within the last year ( 0 Table 1 ), the value increased to $65 \%$ for the years $2008-2010$, but then decreased to $56 \%$ for the years $2011-2013$ (3). Between $23 \%$ and $26 \%$ of participants were able to provide information about participation in a medical examination. The personal dosimetry results were known to approximately $48 \%$ of the participants averaged over all years (2005 - 2007: 39\%; 2008 - 2010: $58 \%$; 2011 -13: 58\%). In the case of purely "in-house" courses, the results of the questionnaire also indicate the quality of the institution.

EU Directive 97/43 [1] also regulates the presence of pregnant women in the controlled area. $39 \%$ of the participants in $2005-2007,58 \%$ in $2008-2010$, and $48 \%$ in $2011-2013$ (3) knew that pregnant women are allowed to work in the controlled area under certain conditions. This parameter shows the greatest increase despite the drop for the period $2011-2013$ (3). The question regarding the limit value for the annual dose for persons occupationally exposed to radiation in category A ( $20 \mathrm{mSv}$ ) was answered correctly by $33 \%$ of participants in the first period, by $41 \%$ for the second period, and by $38 \%$ for the current period. $1.5-4.7 \%$ of participants thought the value was $100 \mathrm{mSv}$ and $9.8-$ $13.2 \%$ could not specify a limit value.

The questions regarding the dose limit value and the authorization for pregnant women to work in the controlled area were also part of the test questions. Immediately after the courses, $95 \%$ and $90 \%$ of the participants, respectively, could answer these questions correctly.

In addition to the questions, desired topics for the current course could be expressed and were then discussed on the basis of the current literature. The main topic requests included dose reduction via modern methods [8], personal radiation protection equipment [9], tumor induction using radiodiagnostics [10], and teleradiology [11]

\section{Discussion \\ $\nabla$}

This study shows an increase in knowledge but a lack of knowledge retention. The level of knowledge also corresponds to the self-assessment of the participants of other courses [12]. The change in the participants' self-assessment over time (32. to 2.9 to 3.1 ) reflects the actual tendency in the retention of knowledge. The time from the first three-year period to the second shows a trend (7/8 questions) toward adequate responses while the trend is reversed for the time from the second period to the third (6/8 questions). The significance level (t-test) is satisfactory in only several cases. Since the trends span the entire range of questions, it is obvious that the level of knowledge has decreased in recent years.

In summary it can be said that organizational radiation protection has improved less than the knowledge of radiation protection, with the exception of the ability to name the radiation protection supervisor. However, the percentage of correct answers averaged over all years was not satisfactory 
for any of the questions. This was also observed in other studies, e. g. by Absi et al. (2011) [13], who found an average value of $58.9 \%$ correctly answered questions (6-12 months after courses). According to the participants, the failure to retain the knowledge that pregnant women are allowed to work in the controlled area was due to the complexity of the regulations. In radiology the known regulation [5] applies, but pregnant women are not allowed to work in the controlled area in nuclear medicine due to the possible incorporation of radioactive substances, and in radiotherapy in the case of photon energies $>10 \mathrm{MeV}$ after a change to the guideline [14].

The X-Ray Ordinance is the central document for radiation protection regulations and is being increasingly read according to the participants. Increased access via the intranet may have helped with distribution.

In 1997 in North Rhine-Westphalia, 55 cardiology practices were inspected by the supervisory authorities [15]. A weak point was the training (now referred to as instruction) that was only conducted in $67 \%$ of the practices. This value corresponds to the maximum three-year value $(2008-2010)$ of $65 \%$ in the present study. However, participants were asked whether they had knowledge of a prior instruction, which is not necessarily indicative of the actual performance of an instruction. It is probable that the current situation has not changed with respect to the situation in 1997 at least with respect to participant awareness. It has proven to be valuable to adapt course content on the basis of the questionnaires. Therefore, for example, the topic "pregnant women in the controlled area" can be discussed by a physician, lawyer, and medical physicist as needed. Since all lecturers are present for the entire course day, the questionnaire results can be discussed repeatedly and viewed from different points of view.

Which optimizations can be derived from the results of this study?

The following main statements can be made:

1. The knowledge of the participants is insufficient. After an initial increase in knowledge, questions are increasingly answered incorrectly.

2. The refresher courses are necessary but may not be retained sufficiently. Compared to the starting level (2005 - 2007), an increase in knowledge in the following years (average $+15 \%$ ) was able to be determined but this then decreased again in the following years $(-8 \%)$. Therefore, mandatory repetition of the courses is important and is customary in Europe. A look at the implementation of the EU directive shows that different course lengths (4-36 hours) and intervals (3-6 years) are considered appropriate [16].

3. The level of knowledge after 5 years is too low (mean value: $50 \%$ correct responses). Consideration should be given to shortening the interval for the renewal of qualification at least for certain groups, including radiation protection officers. To avoid too much repetition, the training time could be reduced.

The study is being continued in this form but some of the questions are to be formulated with greater detail. This applies in particular to data regarding the dissemination of information in the case of changes to the regulations and new radiation protection findings and regarding the position of individual participants in organizational radiation protection.

\section{Conclusion:}

\section{$\nabla$}

The courses do not have the desired effect. This can be increased by the annual instruction. The instruction currently does not seem to be occurring with the mandated quality and quantity. Radiation protection officers in particular need to perform their tasks better. Radiation protection supervisors should be included in training since they are responsible for the organization.

\section{References}

1 Richtlinie 97/43/EURATOM des Rates vom 30. Juni 1997 über den Gesundheitsschutz von Personen gegen die Gefahren ionisierender Strahlung bei medizinischer Exposition und zur Aufhebung Richtlinie 84/466/EURATOM. Amtsblatt Nr. L 180 vom 9.7.1997, 22 - 27

2 Verordnung über den Schutz vor Schäden durch Röntgenstrahlen (Röntgenverordnung) vom 8. Januar 1987 (BGBL. I S.114), in der Fassung der Bekanntmachung vom 30. April 2003 (BGBL. I S. 604)

3 Verordnung über den Schutz vor Schäden durch Röntgenstrahlen (Röntgenverordnung) in der Fassung der Bekanntmachung vom 30. April 2003 (BGBL. I S. 604), die durch Artikel 2 der Verordnung vom 4. Oktober 2011 (BGBL. I S. 2000) geändert worden ist

4 Verordnung über den Schutz vor Schäden durch ionisierende Strahlen (Strahlenschutzverordnung) vom 20. Juli 2001 (BGBL. I S. 1714; 2002 I S. 1459), die zuletzt durch Artikel 5 Absatz 7 des Gesetzes vom 24. Februar 2012 (BGBL. I S. 212) geändert worden ist

5 Richtlinie Fachkunde und Kenntnisse im Strahlenschutz bei dem Betrieb von Röntgeneinrichtungen in der Medizin oder Zahnmedizin vom 22. Dezember 2005 (GMBI 2006, Nr. 22, S. 414) in Kraft getreten am 1. März 2006

6 Prümer BA, Haverkamp U, Fahrmer U. Stand der Kenntnisse im Strahlenschutz vor der Aktualisierung der Fachkunde nach RöV und StrSchV Strahlenther. Onkol 2008; 184: 89

7 Bundesarztregister. 2009, Kassenärztliche Bundesvereinigung

8 Widmann G, Fasser M, Schullian $P$ et al. Substantial dose reduction in modern multi-slice spiral computed tomography (MSCT)-guided craniofacial and skull base surgery. Fortschr Röntgenstr 2012; 184 : $136-142$

9 Pichler T, Schöpf T, Ennemoser O. Radiation protection clothing in X-ray diagnosis - comparison of attenuation equivalents in narrow beam and inverse broad-beam geometry. Fortschr Röntgenstr 2011; 183 : $470-476$

10 Hammer GP, Seidenbusch MC, Schneider K et al. Cancer incidence rate after diagnostic X-ray exposure in 1976-2003 among patients of a university children's hospital. Fortschr Röntgenstr 2010; 182: 404-414

11 Rosenberg C, Langner S, Rosenberg B et al. Medical and legal aspects of teleradiology in Germany. Fortschr Röntgenstr 2011; 183: 804-811

12 Leppek LR, Madsack B, Klose K. Aktualisierungskurse im Strahlenschutz Wahrnehmung und Selbsteinschätzung der Kursteilnehmer. Fortschr Röntgenstr 2008; 180: . DOI: 10.1055/s-2008-1074065

13 Absi EG, Drage NA, Thomas HS et al. Continuing dental education in radiation protection: knowledge retention following a postgraduate course. Eur J dent Educ 2011; 15: 189-192

14 Strahlenschutz in der Medizin - Richtlinie zur Verordnung über den Schutz vor Schäden durch ionisierende Strahlen (Strahlenschutzverordnung - StrlSchV) vom 17. Oktober 2011 (GMBI. 2011, Nr. 44-47, S.867) in Kraft getreten am 1. November 2011

15 Ewen K, Hannig P, Lauber I et al. Strahlenbelastung an Herzkatheterarbeitsplätzen. Hrsg.: Nordrhein-Westfalen: Landesanstalt für Arbeitsschutz; 1997

16 Fahrmer A, Haverkamp U, Miller A et al. Experiences with EU Council directive 96/29 and purposes. Acta Chirurgica Latviensis Supplement 2010; 10/1: 72 